\title{
EVALUATION OF Merremia tridentata MUCILAGE AS BINDING AGENT INTABLET DOSAGE FORMS
}

\author{
M. Vidyavathi*, K. Radha, A. Rajyalakshmi and R. Ramya \\ Institute of Pharmaceutical Technology, Sri Padmavati MahilaVisvavidyalayam, \\ Tirupati-517502, A.P., India \\ *E-mail: vidyasur@rediffmail.com
}

\begin{abstract}
An increasing interest in the use of natural polymers or gums in pharmaceutical formulations focusing the tremendous orientation to discover and extract such gums. The pharmaceutical industry is ever thirsty to satisfy patient's therapeutic needs by utilizing inactive excipients along with active ingredients in formulation development. Binders are added to tablet formulations to add cohesiveness to powders thereby providing the necessary bonding to form granules which under compaction form a compact mass as tablet. Binders are also essential to achieve the hardness of the tablet. The development of new excipients for potential use as binding agent in tablet formulations continues to be of interest. The present paper consisted of the evaluation of mucilage of Merrimia tridentata roots for its binding property in solid dosage forms by using starch as a standard binder. Ibuprofen was used as a model drug and tablets were prepared using mucilage obtained from roots of Merremia tridentate as a test binder and starch as standard binder by wet granulation method. The granules were evaluated for flow properties, drug excipient compatibility and compressibility index and tablets were evaluated for weight variation, hardness, friability, disintegration time and dissolution rate. The similarity factor was determined for comparison of dissolution profiles of test and standard tablets. It has been found from the present study that the roots of plant Merremia tridentata has a good mucilage content which may be taken as a good natural source of mucilage for better binding properties with comparable flow properties, disintegration time, hardness and release rate similar to starch.
\end{abstract}

Keywords: Compaction, Mucilage, Merremia tridentata, Binder, Starch, Tablets.

○ RASĀYAN. All rights reserved

\section{INTRODUCTION}

There is an increasing interest in natural gums to use in formulations. The pharmaceutical industry is ever thirsty to satisfy patient's therapeutic needs by utilizing inactive excipients along with active ingredients in formulation development. Pharmaceutical excipients are substances other than the pharmacologically active drug or prodrug which are included in the preparation of formulations or are contained in a finished pharmaceutical dosage form. ${ }^{1}$ The excipients play major role to maintain the quality of a formulation and bioavailability of drug from tablets. Binders are added to tablet formulation to impart the adhesiveness of the powder during the initial granulation and to the tablet after compression. ${ }^{2}$ The development of new binding agents for tablet formulations continues to be of interest. This is because different binding agents can be useful in achieving various tablet mechanical strength and drug release properties for different purposes. In recent times, increasing attention has been given to the application of gums of various sources as pharmaceutical excipients. Plant gums are widely used in diverse applications including as binding agent for the formulation of pharmaceutical dosage forms. ${ }^{3,4}$ The natural excipients are biocompatible, cheap and easily available and are preferred to synthetic compounds. ${ }^{5-7}$ Mucilages from Chlorophytumbrivilianum, ${ }^{8}$ Asparagus racemosus and Cassia sopherav, ${ }^{9}$ Plantagoovata, ${ }^{10}$ Delonixregia endospermic mucilage ${ }^{11}$ and mucilage of seeds of different plants were successfully evaluated for their granulating and binding properties in tablets. ${ }^{12-16}$ The present study was aimed at extraction of mucilage from the roots of the plant Merrimea tridentata and evaluation of its binding properties in tablet dosage forms in comparison with starch. This plant is abundantly available in Tirumala hills and roots are found to have more mucilage content. This plant is used for arthritis, hemiplegia, hemorrhoids, urinary diseases 
and inflammation ${ }^{17,18}$ and its safety was also studied by its acute toxicity studies. ${ }^{19}$ Mucilages are the most commonly used excipients in various pharmaceutical formulations as thickening, binding, suspending, disintegrating agents. ${ }^{20}$ The tablets were prepared using mucilage obtained from roots of Merremia tridentata as test binder and starch as standard binder. Then, these were evaluated for different in vitro parameters and results were compared by calculating similarity factor.

\section{Procurement of plant}

\section{EXPERIMENTAL}

The fresh plant materials were collected, washed with water to remove dirt and debris, and dried. The weighed quantity $(50 \mathrm{gm})$ of dried roots were taken and powdered by milling. Then, the powdered material was soaked in $500 \mathrm{ml}$ of petroleum ether for $24 \mathrm{hrs}$ in a round bottomed flask. The next day, this was subjected to reflux for $1 \mathrm{hr}$.Then, it was cooled and filtered. Repeated the procedure for 3 times and was subjected to solvent evaporation by using rotary flash evaporator. Thus the roots of the plants were defatted.

\section{Extraction of mucilage}

The marc was collected from above process and was soaked in $500 \mathrm{ml}$ of water in a round bottomed flask. Acetic acid was added to it until the $\mathrm{P}_{\mathrm{H}}$ was adjusted to 4-5. It was heated for 15 minutes at a temperature of $60-70^{\circ} \mathrm{C}$, then it was cooled and filtered. Acetone was added to the filtrate in 1:1 ratio and kept aside for $24 \mathrm{hrs}$, and it was centrifuged for 10-15 mins. at 1500-2000rpm. Repeated the procedure until the mucilage was obtained and it was dried. ${ }^{21-23}$ Then the dried mucilage was tested for carbohydrates using Molisch test and Ruthenium red test.

\section{Formulation of tablets}

The tablets were prepared by wet granulation method using Ibuprofen as model drug as per formula shown in Table-1.Test tablets contained mucilage as binder and standard tablets contained starch as binder. Starch is used as a good binder at $10 \%$ concentration, hence $10 \%$ mucilage was used to prepare tablets.

Table-1: Composition of Prepared Tablets

\begin{tabular}{c|c|c|c}
\hline S. No. & Name of Ingredient & Standard Tablets (mg) & Test Tablets (mg) \\
\hline 1 & Ibuprofen & 250 & 250 \\
\hline 2 & Lactose & 150 & 150 \\
\hline 3 & Starch & 15 & 15 \\
\hline 4 & Talc & 15 & 15 \\
\hline 5 & Magnesium stearate & 15 & 15 \\
\hline 6 & Starch paste & $10 \%$ & - \\
\hline 7 & Dried Mucilage & - & $10 \%$ \\
\hline
\end{tabular}

\section{Preparation of granules}

The binder solution was prepared by dissolving the dried mucilage of Merremia tridenteta in water at $10 \% \mathrm{w} / \mathrm{v}$ concentration for test tablets and $10 \%$ starch solution for standard tablets. The granules were prepared separately by wet granulation process using two binders. The drug, lactose, and starch were mixed thoroughly, and a sufficient volume of $10 \% \mathrm{w} / \mathrm{v}$ of mucilage of Merremia tridenteta for test and $10 \%$ starch solution for standard was added slowly to the powder blend and kneading was performed until formation of wet mass with enough cohesiveness is obtained. The wet mass was forced through a no. 10 sieve and obtained granules were dried at $50^{\circ} \mathrm{C}$. The granules were used to perform drug-excipient compatibility studies using UV scan and FT-IR analysis and also evaluated for flow properties, compressibility index. 


\section{Evaluation ofgranules ${ }^{24}$ \\ Angle of repose}

The flow characteristics are measured by angle of repose. Improper flow of powder is due to frictional forces between the particles. These frictional forces are quantified by the angle of repose. Angle of repose is defined as the maximum angle possible between the surface of a pile of the powder and horizontal plane. It was determined by fixed funnel method.

Angle of repose $\tan \theta=\mathrm{h} / \mathrm{r}$

Where, $\mathrm{h}=$ height of the pile; $\mathrm{r}=$ radius of the base of the pile; $\theta=$ angle of repose

\section{Bulk density}

Weighed quantity of the granules was taken in a graduated cylinder. Volume (V) was measured and noted without disturbing the cylinder and bulk density was calculated using the following equation:

Bulk density $(\mathrm{BD})\left(\mathrm{g} / \mathrm{cm}^{3}\right)=$ weight of the powder $(\mathrm{W}) /$ volume of packing $(\mathrm{V})$

\section{i. True density}

The tapping method was used to determine the tapped density, in which the cylinder containing known amount (W) of granules was subjected to a fixed number of taps(approximately 100) until the bed of granules had reached the minimum. The final volume after tapping ' $\mathrm{V}_{0}$ ' was recorded and the tap density was calculated by the following equation:

True density $(\mathrm{TD})\left(\mathrm{g} / \mathrm{cm}^{3}\right)=\mathrm{W} / \mathrm{V}_{0}$

\section{ii. Compressibility index(Carr's index)}

This property is also known as compressibility. It is indirectly related to the relative flow rate, cohesiveness and particle size. It is simple, fast and popular method of predicting powder flow characteristics. (CI) or Carr's index value of granules was computed according to the following equation:

Carr's Index $(\mathrm{CI})=\frac{(\mathrm{TD}-\mathrm{BD})}{\mathrm{TD}} \times 100$

iii. Hausner's ratio:

Hausner's ratio of granules was determined by comparing the tapped density to the bulk density using the equation:

$$
\text { Hausner's ratio }=\frac{\text { true density }}{\text { bulk density }}
$$

\section{iv. Drug -excipient compatibility studies}

The compatibility between drug and mucilage was studied using FTIR analysis by obtaining the spectra for drug, mucilage and granules.

\section{Manufacturing of tablets}

The prepared granules were mixed with talc, zinc stearate as lubricant and antiadherent, and were compressed by rotary single tablet punching machine. Then prepared tablets (both standard \& test) were evaluated for following parameters.

\section{Evaluation of tablets}

\section{a. Weight variation}

20 tablets were selected randomly and individually weighed using an electronic balance and the average weight was calculated. The uniformity of weight was determined according to IP specifications. As per IP limits, not more than two of the individual tablet weight deviate from average weight by more than twice the percentage. 


\section{b. Hardness}

Tablets required certain amount of strength or hardness and resistance to withstand mechanical shocks of handling during packing and shipping. Tablet hardness is the force required to break a tablet in a diametric compressions test. 10 tablets were taken and hardness was determined with Mansanto hardness tester. The average hardness is expressed in $\mathrm{Kg} / \mathrm{Cm}^{2}$.

\section{c. Disintegration Time}

The disintegration test was carried out using USP tablet disintegration test apparatus. The disintegration time of 6tablets, that is the time at which no residue of tablet remains on mesh of apparatus was noted. Then the average disintegration time was calculated for both test and standard tablets.

\section{d. Friability}

Tablets were subjected to combined effects of abrasive and shock by utilizing a plastic chamber that revolves at $25 \mathrm{rpm}$ dropping the tablets at a distance of six inches with each revolution using Roche friabilator. A pre-weighed (W1) 10 tablets were placed in the friabilator which was operated for 100 revolutions. The tablets were dusted and reweighed (W2). The percentage loss during the test was calculated using below formula. Tablets that lose less than 0.5 to $1 \%$ of their weights are considered acceptable:

$$
\% \text { loss in Friability }=\mathrm{W} 1-\mathrm{W} 2 / \mathrm{W} 1 * 100
$$

\section{e. Dissolution rate}

The USP basket type dissolution test apparatus was used for in vitro release studies of prepared tablets. One tablet was placed in a basket fixed to a rod and it was dipped in $900 \mathrm{ml}$ of $\mathrm{P}_{\mathrm{H}} 7.2$ buffer taken in a dissolution vessel.The dissolution medium was stirred at $50 \mathrm{rpm}$ and maintained at constant temperature $\left(37 \pm 1^{0}\right)$.At predetermined time intervals, $2 \mathrm{ml}$ of samples were withdrawn and concentration of drug was estimated using UV spectrophotometer at $262 \mathrm{~nm}$. An equal volume of fresh dissolution medium was replaced after withdrawal of each sample to maintain sink conditions.

\section{Statistical analysis}

All tests were performed thrice and its mean values were noted along with standard deviation. Statistical analysis was done to compare the results of two tablet formulations (test and standard) using T-test. At $95 \%$ confidence level, the $\mathrm{p}$ value lower than or equal to 0.1 was considered as the limit of significance.

\section{Similarity factor for comparison of dissolution profiles}

$\mathrm{f} 1$ and $\mathrm{f} 2$ are the two factors representing dissimilarity and similarity factors respectively to compare the dissolution profiles by mathematical approach. Determination of $\mathrm{f} 2$ is simplest method for comparison of two dissolution profiles. This was introduced by Moore and Flanner,adopted by the centre for drug evaluation and research (USFDA) and by human medicines evaluation unit of the European agency for the evaluation of medical products (EMEA).

The similarity factor $\mathrm{f} 2$ is defined as a logarithmic reciprocal square root transformation of one plus the mean squared (the average sum of squares) differences of drug percent dissolution between test and standard products. ${ }^{25,26}$

$$
\begin{aligned}
& \left.\mathrm{f} 1=\left\{\left|\sum_{\mathrm{t}=1}{ }^{\mathrm{n}}\right| \mathrm{R}_{\mathrm{t}}-\mathrm{T}_{\mathrm{t}} \mid\right] /\left[\sum_{\mathrm{t}=1}{ }^{\mathrm{n}} \mathrm{R}_{\mathrm{t}}\right]\right\}^{\times} 100 \\
& \left.\mathrm{f} 2=50^{\times} \log \left\{1+[1 / \mathrm{n}] \sum\left|\mathrm{R}_{\mathrm{t}}-\mathrm{T}_{\mathrm{t}}\right|^{2}\right]^{-0.5 \times} 100\right\}
\end{aligned}
$$

Where $\mathrm{n}=$ number of dissolution time points, $\mathrm{R}_{\mathrm{t}}=\%$ drug dissolved from standard formulation, $\mathrm{T}_{\mathrm{t}}=\%$ drug dissolved from test formulation, $\mathrm{T}=$ Time. The values of $\mathrm{f} 1<15$ and $\mathrm{f} 2>50$ are indicative of the similarity of dissolution profiles. ${ }^{27}$ The equation $\mathrm{f} 2$ is only applicable for comparing curves in which the average difference between $\mathrm{R}$ and $\mathrm{T}$ is less than 100 . 


\section{RESULTS AND DISCUSSION}

In the present study, the mucilage extracted from roots of Merrimia tridentata was used as binding agent in tablet dosage forms as the natural products are nontoxic, biocompatible and cheap. ${ }^{28}$ The dried coarsely powdered roots of Merrimia tridentata was used to prepare mucilage using acetone as mucilage precipitating agent. The chemical nature of mucilage was found as carbohydrate, as it has shown positive results in Molisch test and Ruthenium red test similar to starch.

The prepared granules were evaluated for flow properties using angle of repose, bulk density, tap density, compressibility index, Hausner's ratio and the results are shown in Table-2. It was observed that granules of test and standard possessed good to excellent flow properties based on the value of angle of repose, bulk density, tap density, compressibility index, and Hausner's ratio as per Table-2. The test granules have shown flow properties similar to standard granules which suggested that the prepared mucilage contributed to flow properties of granules equal to starch. And, it was also observed that there was no significant difference in flow properties of both standard and test granules( $\mathrm{p} \leq 0.05)$.

Table-2: Results of different In Vitro parameters

\begin{tabular}{|c|c|c|c|}
\hline S. No. & Parameter & $\begin{array}{c}\text { Standard } \\
\text { Mean } \pm \text { S.D }\end{array}$ & $\begin{array}{c}\text { Test } \\
\text { Mean } \pm \text { S.D }\end{array}$ \\
\hline \multicolumn{4}{|c|}{ Granules } \\
\hline 1 & Angle of repose $(\theta)$ & $22.5 \pm 0.07$ & $26.5 \pm 0.11$ \\
\hline 2. & Bulk density $(\mathrm{gm} / \mathrm{cc})$ & $0.45 \pm 0.09$ & $0.39 \pm 0.03$ \\
\hline 3. & Tapped density(gm/cc) & $0.51 \pm 0.02$ & $0.45 \pm 0.05$ \\
\hline 4. & Carr's index & $12.6 \pm 0.07$ & $13.3 \pm 0.04$ \\
\hline 5. & Hausner's ratio & $1.14 \pm 0.08$ & $1.15 \pm 0.12$ \\
\hline \multicolumn{4}{|c|}{ Tablets } \\
\hline 6. & Weight variation (\%) & $2.96 \pm 1.61$ & $1.68 \pm 0.98$ \\
\hline 7. & Hardness $\left(\mathrm{Kg} / \mathrm{cm}^{2}\right)$ & $3.02 \pm 0.47$ & $2.04 \pm 0.36$ \\
\hline 8. & Friability $(\%)$ & $0.390 \pm 0.001$ & $0.198 \pm 0.001$ \\
\hline 9. & Disintegration time (min) & $9.33 \pm 1.210$ & $3.33 \pm 1.032$ \\
\hline
\end{tabular}

All these results indicated that the granules prepared using mucilage of Merremia tridentata possessed satisfactory flow properties, compressibility and porosity.

The drug and excipient compatibility studies were conducted by FTIR. The FTIR spectrum of Ibuprofen (Figure-1) demonstrated that the characteristic absorption peaks were found for carboxylic acids at 2921.88 ,alkanes at 2870.60 ,alkynes at 2178.55 , ketones at 1718.96 , aromatic ring at $1507.58, \mathrm{C}-\mathrm{H}$ stretches of alkanes was at 1068-667.05.FT-IR spectrum of mucilage(Figure-2) demonstrated that the characteristic absorption peaks were found for $\mathrm{N}-\mathrm{H}$ amine stretches at $3420.64, \mathrm{C}=\mathrm{O}$ at 2926.51, alkynes at 2163.49,aromatic rings at 1645.21 ,cyanides C-N at 1250.98,C-H alkanes at 1022.61 to 603.60.FT-IR spectrum of test granules (Figure-3) demonstrated that the characteristic absorption peaks were found for alcohols, phenols $(\mathrm{O}-\mathrm{H})$ at $2871.55, \mathrm{C}=\mathrm{O}$ acids at 2922.30, alkynes at 2173.91, O-H ketones at 1718.80, C-H alkanes at $1019.12-668.3$. These peaks were similar to pure drug spectrum indicated the compatibility between the drug and mucilage. Thus, based on discussion of FTIR spectra, it was found that Ibuprofen did not lose its spectral characteristics after preparing granules using mucilage. It can be concluded that Ibuprofen is compatible with test mucilage in present study.

50 tablets were prepared with test and standard granules and evaluated for weight variation, hardness, friability, disintegration time and in vitro dissolution rate.

The percentage weight variation as mentioned in the Table- 2 was less in test tablets prepared by mucilage compared with standard tablets prepared by starch. This indicated that more uniformity in weight and drug content in test tablets. The less weight variation also suggested good cohesiveness between granules by test binder. As per the statistical analysis there was no significant difference $(\mathrm{p}<0.1)$ between weight variation of test and standard tablets. The average hardness of tablets prepared using test mucilage was 
less than the tablets prepared by standard(Table-2) and as per statistical analysis there was no significant difference $(\mathrm{p}<0.1)$ between test tablets and standard tablets confirmed that the binding characteristics of mucilage was similar to that of starch.

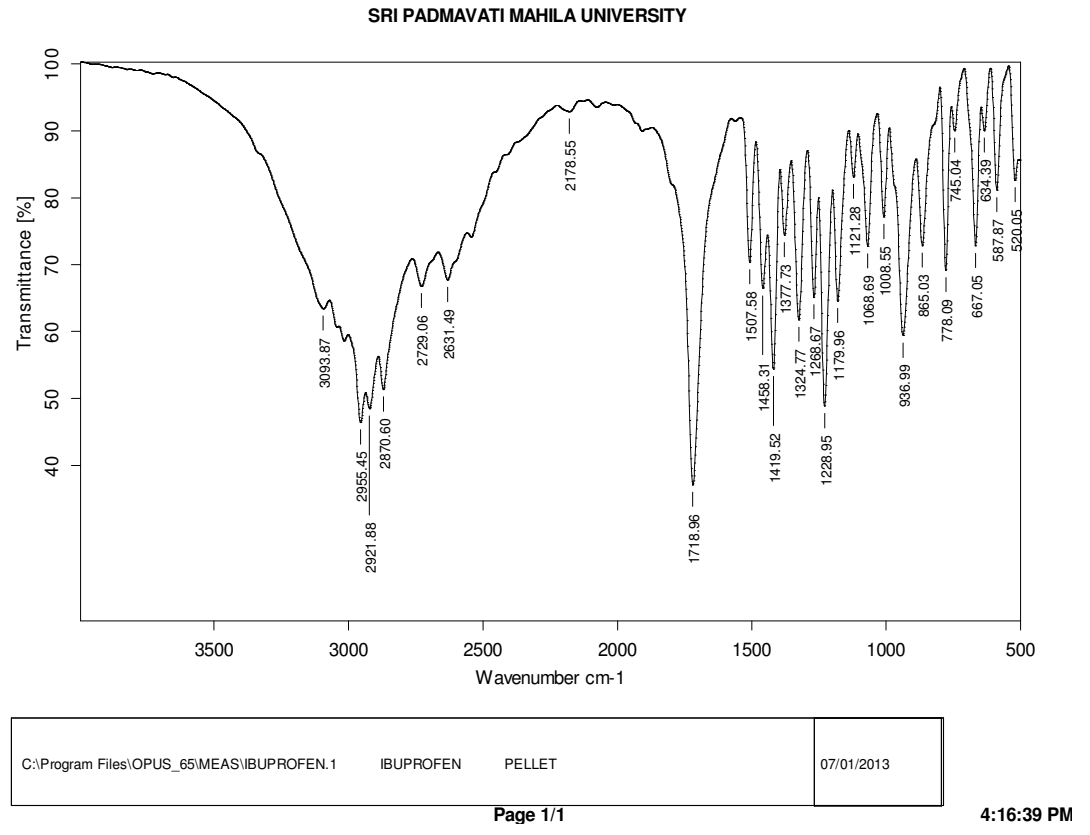

Fig.-1: FTIR Spectrum of Ibuprofen

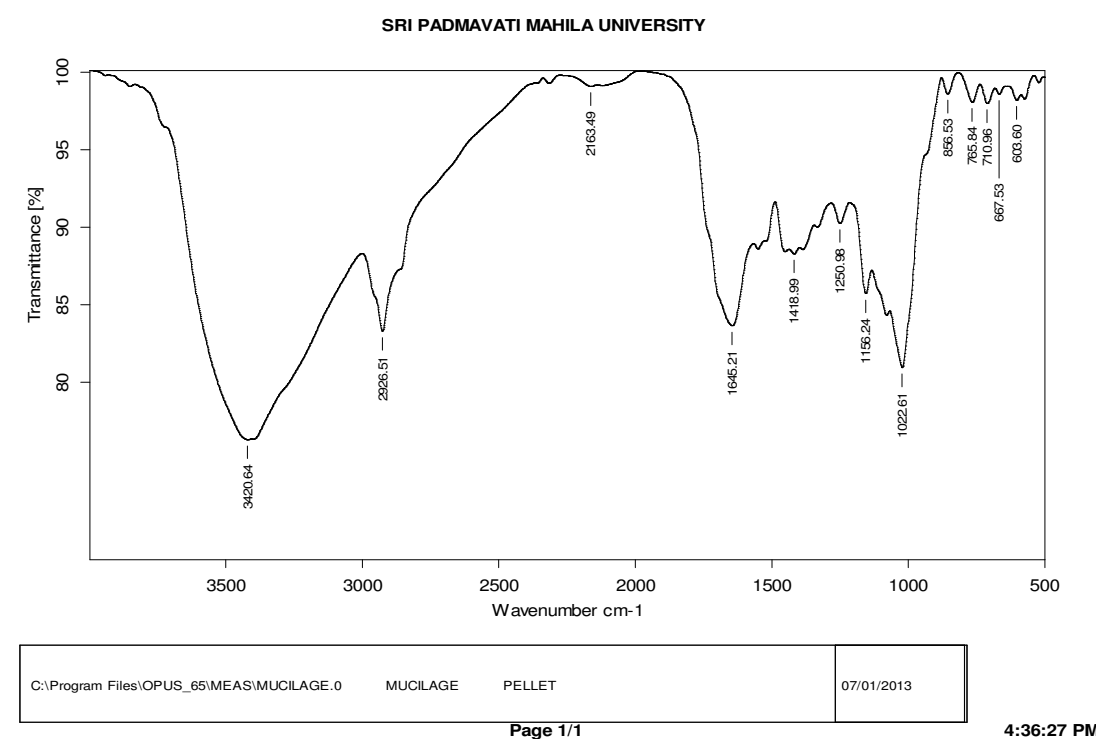

Fig.-2: FTIR Spectrum of standard mucilage

The average percentage loss in friability as shown in the Table- 2 was found to be with in official limits for both the standard and test tablets. This loss was less in test tablets than the standard, however there is no significant difference between test and standard tablets $(\mathrm{p}<0.10)$. The average disintegration time as shown in the Table- 2 was less for test tablets than standard tablets. It suggested that there is contribution of test mucilage in the disintegration of tablets. The fast disintegration of test tablets might be due to any 
of mechanisms of disintegration by absorption of water or by easy burst of tablets. It was observed that there is a significant difference between disintegration time of test and standard tablets $(\mathrm{p}<0.05)$.

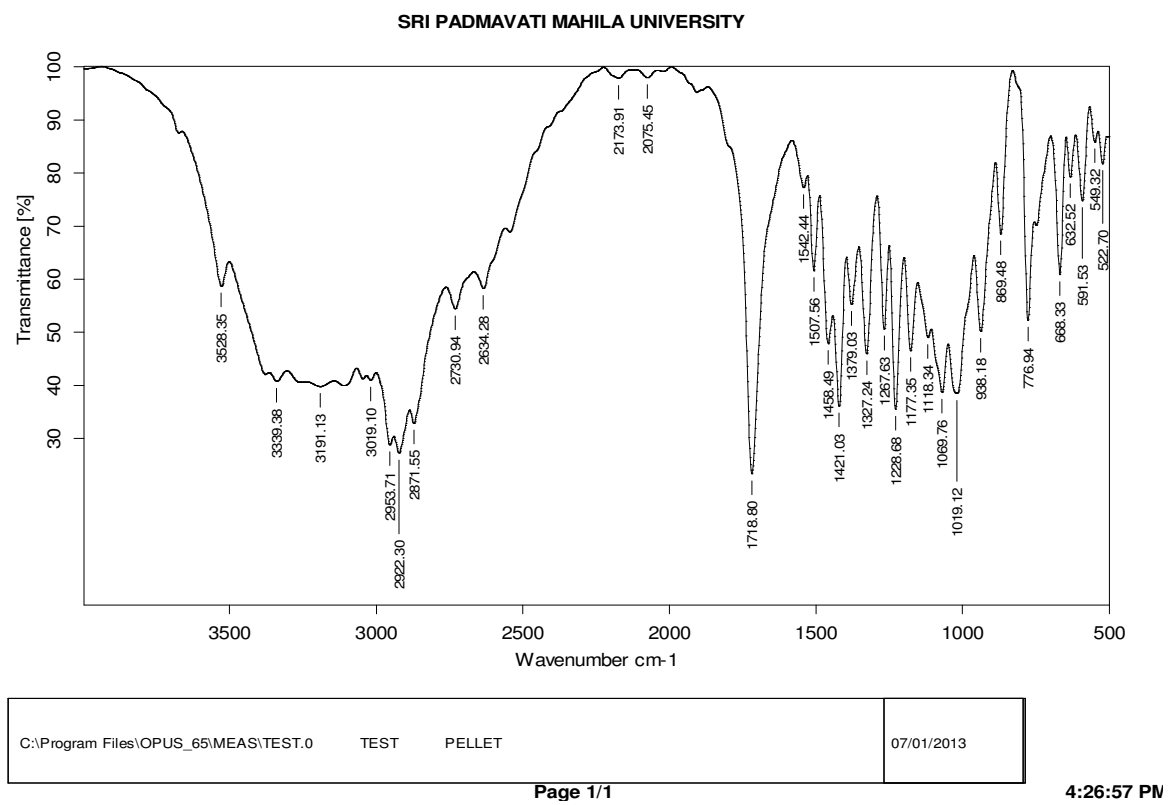

Fig.-3: FTIR Spectrum of test granules

The dissolution profiles indicated that $92 \%$ of drug was released within $60 \mathrm{~min}$. from test tablets where as $85 \%$ of drug was released in $60 \mathrm{~min}$. from standard tablets might be due to fast disintegration of test tablets( Table-3 and Figure-4). According to $\mathrm{T}_{50 \%}$, and the $\%$ drug dissolved in 60 minutes, it was found that there was no significant difference between two tablet formulations.

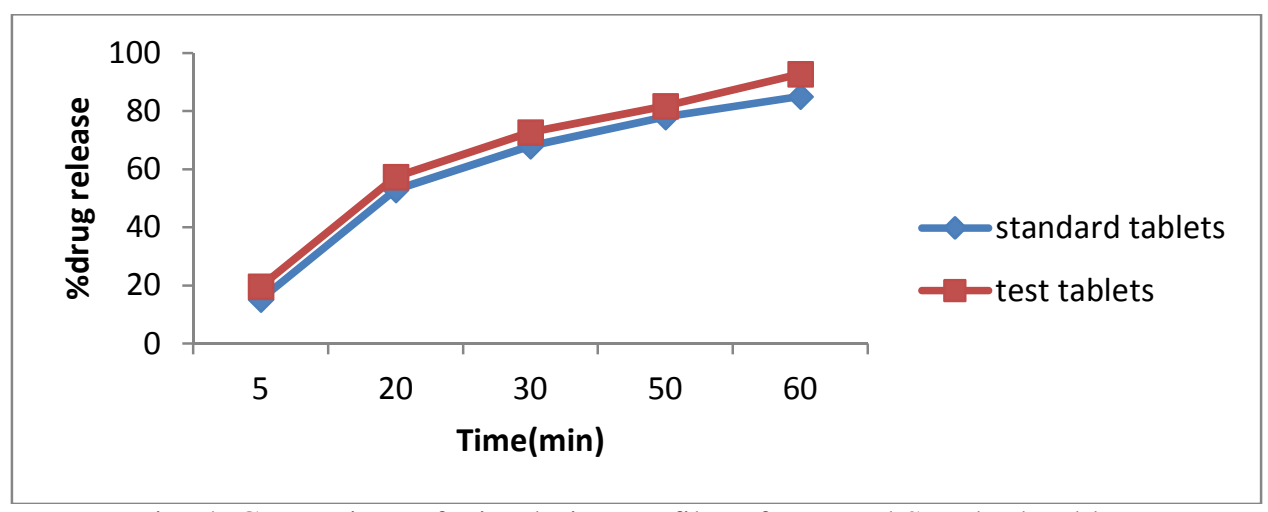

Fig.-4: Comparison of Dissolution Profiles of Test and Standard Tablets

Table-3: Percentage Drug Dissolved from Test and Standard Tablets

\begin{tabular}{c|c|c|c}
\hline \multirow{2}{*}{ S. No. } & Time(Min.) & \multicolumn{2}{|c}{ \%Drug Dissolved } \\
\cline { 3 - 4 } & & $\begin{array}{c}\text { Standard Tablets } \\
(\text { Mean } \pm \text { SD) }\end{array}$ & $\begin{array}{c}\text { Test Tablets } \\
(\text { Mean } \pm \text { SD) }\end{array}$ \\
\hline 1. & 5 & $15.2 \pm 0.17$ & $19.72 \pm 0.09$ \\
\hline 2. & 20 & $52.91 \pm 0.19$ & $57.35 \pm 0.11$ \\
\hline 3. & 30 & $68.02 \pm 0.02$ & $72.67 \pm 0.04$ \\
\hline 4. & 50 & $78.05 \pm 0.31$ & $81.79 \pm 0.17$ \\
\hline 5. & 60 & $85.06 \pm 0.11$ & $92.87 \pm 0.12$ \\
\hline
\end{tabular}


Similarity factor f2 calculated for test and standard tablets using in vitro dissolution was 69.42, which indicated, similarity between test and standard tablets. Thus, it was confirmed that Merremia tridentata mucilage has similar binding characteristics to that of starch as there is no significant difference in the results of different invitro parameters and dissolution profiles.

\section{CONCLUSION}

It was found from the present study, that the roots of the plant Merremia tridentata contains a good mucilage which was evaluated for its binding property in tablet dosage forms using Ibuprofen as model drug. The results in present study demonstrated that this mucilage has good binding properties similar to starch and is also economical compared with starch. The similarity factor between test and standard tablets was found to be 69.42 which is greater than 50 indicated that the test dissolution profile is similar to standard profile. Hence, this mucilage can be used as a suitable binding agent in the preparation of tablets with comparable flow properties, disintegration time, hardness and release rate at low cost.

\section{REFERENCES}

1. M.U. Uhumwangho, R.S.Okor, F.E. Eichie, C. M.Abbah . Afr. J. Biotechnol., 5(20), 1950 (2006)

2. R.E. Gordan, T.W. Rashanka, D.E. Fonner, N.R Anderson, and G. S. Bankar, In: Lachman L, Liberman H.A and J. B. Schwartz ed. Pharmaceutical dosage forms.Tablets, Vol.11,New York: Marcel decker,245(1999).

3. O.A. Odeku, O.A. Itiola , Drug Dev Ind Pharm., 28(3), 329 (2002).

4. O.A. Odeku, O.A. Itiola, Drug Dev Ind Pharm., 29(3), 311 (2003).

5. N.S. Bhunvara, and M.L. Khorana, Drugs, 22, 500 (1985).

6. G.T. Kulkarni, K. Gowthamarajan, R.R. Dhobe,F. Yohanan and B. Suresh, Drug Deliv.,12,201 (2005).

7. H.K. Kakrani, and N.K. Jain, Ind J. Hosp. Pharmacist, XVIII(3), 100 (1981).

8. S.L. Deore, and S.S. Khadabadi, Rasayan J.Chem., 1, 887 (2008).

9. G.T. Kulkarni, K.Gowthmarajan, G.B. Rao and B. Suresh, J. Sci and Ind. Res., 1, 329 (2002).

10. G.T. Kulkarni, K.Gowthmarajan, G.B. Rao and B. Suresh, Ind. Drugs, 39, 422 (2002).

11. R.H. Kale, U.M. Joshi, D.P. Ambhore and G.R. Sitaphale, Int J. Chem. Tech. Res., 1, 11 (2009).

12. I.K .Yadav, D. Jaiswal, H.P. Singh, D. Chandra and D.A. Jain, J. Pharm. Res., 2, 1281 (2009).

13. F.E. Eichie and A.E.Amalime, African J. Biotechnol., 6, 2208 (2001).

14. S. Singh and S. Singh, Int. J. Pharm. Sci. and Res., 1,118 (2010).

15. B. Anroop, B. Ghosh, V.Parcha, S. Vasanti, Int. J. Pharm. 325,191 (2006).

16. B.V. Ghule, G.D. Darwhekar, D.K. Jain, P. G.Yeole . Ind. J. Pharm. Sci., 68,566(2006).

17. A. Munish, Ashokkumar, Y. Parvinder, S.Kuldeep, Int. J. of Biol. Macromol., 57, 105(2013) .

18. S. Vidya, P.Vandana, P .Archana and S. Prafulla, Int. J. of Pharm..Res.,1(4),56 (2009).

19. A .Sreedevi, R.Radha, K .Bharathi, Natural Products, An Ind. J., 4(2), 174 (2008)

20. M. Rishabha, S. Pranathi, and G.T. Kulkarni , Adv. in Biolog. Res., 5(1),1( 2011).

21. S. Senthil, R.Gopalakrishanan, S. Ramajayam, M. Srahul, Int. J. of Chem. Tech Res., 2(1),436(2010).

22. S. Majid, M.S. Katayoun, A. Farshad, F. Safed, A.Gholamreza. Acta Pharm.,60, 339 (2010).

23. K. Gowthamarajan, G.T. Kulkarni, A. Muthukumar, N. Mahadevan, M.K. Samanta and B. Suresh, Int J. Pharm Exc, 4(1), 16(2002)

24. C. V. S. Subramanyam, Micromeritics, In:Text book of Physical Pharmaceutics, $2^{\text {nd }}$ edition, Vallabh Prakashan, Delhi, 226, (2000)

25. P.Costap, J.M. Labo, Eur. J. Pharm. Sci., 13,123 (2001).

26. M.C. Gohel , M.K. Panchal, Dissolution Technologies,18, (2002).

27. V.P. Shah, Y. Tsong, P. Sathe, J.P . Liu. Pharm Res., 15,889 (1998).

28. K.P.R. Chowdary, P. Mahapatra, M.N. Muralikrishna, Rasayan J.Chem., 1(1), 99 (2008).

[RJC-1614/2017] 